\title{
Management of hyperkalemia in the acutely ill patient
}

\author{
François Dépret ${ }^{1,2,3}$, W. Frank Peacock ${ }^{5}$, Kathleen D. Liu' ${ }^{6}$ Zubaid Rafique ${ }^{5}$, Patrick Rossignol ${ }^{4,7}$ \\ and Matthieu Legrand ${ }^{1,2,3,4^{*}}$
}

\begin{abstract}
Purpose: To review the mechanisms of action, expected efficacy and side effects of strategies to control hyperkalemia in acutely ill patients.

Methods: We searched MEDLINE and EMBASE for relevant papers published in English between Jan 1, 1938, and July 1, 2018, in accordance with the PRISMA Statement using the following terms: "hyperkalemia," 'intensive care," "acute kidney injury,"'acute kidney failure," "hyperkalemia treatment,"'"renal replacement therapy," 'dialysis," 'sodium bicarbonate,"'"emergency,"'acute." Reports from within the past 10 years were selected preferentially, together with highly relevant older publications.

Results: Hyperkalemia is a potentially life-threatening electrolyte abnormality and may cause cardiac electrophysiological disturbances in the acutely ill patient. Frequently used therapies for hyperkalemia may, however, also be associated with morbidity. Therapeutics may include the simultaneous administration of insulin and glucose (associated with frequent dysglycemic complications), $\beta-2$ agonists (associated with potential cardiac ischemia and arrhythmias), hypertonic sodium bicarbonate infusion in the acidotic patient (representing a large hypertonic sodium load) and renal replacement therapy (effective but invasive). Potassium-lowering drugs can cause rapid decrease in serum potassium level leading to cardiac hyperexcitability and rhythm disorders.
\end{abstract}

Conclusions: Treatment of hyperkalemia should not only focus on the ability of specific therapies to lower serum potassium level but also on their potential side effects. Tailoring treatment to the patient condition and situation may limit the risks.

Keywords: Hyperkalemia, Intensive care, Emergency, Renal replacement therapy, Acute kidney injury

\section{Background}

Hyperkalemia is a potentially life-threatening electrolyte abnormality [1-3]. Although there is no internationally agreed upon definition for hyperkalemia, the European Resuscitation Council defines hyperkalemia as a plasma level $>5.5 \mathrm{mmol} / \mathrm{L}$ and severe hyperkalemia as $>6.5 \mathrm{mmol} / \mathrm{L}$ [4]. Hyperkalemia is associated with poor outcomes in many different settings, including the acutely ill patient $[5,6]$. In acute hyperkalemia, the primary mortality risks are cardiac rhythm or conduction

\footnotetext{
*Correspondence: matthieu.legrand@aphp.fr

${ }^{1}$ GH St-Louis-Lariboisière, Department of Anesthesiology and Critical Care and Burn Unit, St-Louis Hospital, Assistance Publique-Hopitaux de Paris, Paris, France

Full list of author information is available at the end of the article
}

abnormalities [7, 8]. However, the actual causes of death in patients with hyperkalemia are poorly described, and the causal relationship between hyperkalemia and outcome remains controversial.

The aim of this review is first to describe mechanisms and the risk-benefit ratio of different strategies of hyperkalemia treatment and second, to propose a tailored treatment strategy. This will include a discussion of the effectiveness as well as complications of renal replacement therapy, limiting the risk of hypoglycemia with judicious insulin and glucose administration, and the potential benefit and risks of hypertonic sodium bicarbonate. 


\section{Methods}

We searched MEDLINE and EMBASE for relevant papers published in English between Jan 1, 1938, and July 1, 2018, in accordance with the PRISMA Statement using the following terms: "hyperkalemia," "intensive care," "acute kidney injury," "acute kidney failure," "hyperkalemia treatment," "renal replacement therapy," "dialysis," "sodium bicarbonate," "emergency," "acute." Reports from within the past 10 years were selected preferentially together with highly relevant older publications.

\section{Association between hyperkalemia and outcomes}

The potassium ion $\left(\mathrm{K}^{+}\right)$is the most abundant cation in the body. There is an estimated total reserve of 3000$4000 \mathrm{mmol}$ in adults, of which only $60 \mathrm{mmol}(2 \%)$ are extracellular [9]. Hyperkalemia is associated with poor outcomes in many different settings: in the general population $[5,6]$, in patients with cardiac and renal disease [10-13] and in critically ill patients [14]. In a retrospective study of hospitalized patients, Khanagavi et al. [5] found that acute kidney injury (AKI) and prolonged hyperkalemia are independent predictors of in-hospital mortality. In acute myocardial infarction, a serum potassium above $4.5 \mathrm{mmol} / \mathrm{L}$ is associated with a higher mortality [11]. More recently, Legrand et al. [15] identified that a serum potassium $>4.5 \mathrm{mmol} / \mathrm{L}$ in heart failure patients admitted to the emergency department (ED) is associated with an increased risk of death.

The net effect is a U-shaped mortality curve associated with potassium abnormalities [16-19]. Several observational studies have identified hypokalemia as an independent risk factor for poor outcome [13, 16-19]. This association raises concern regarding the potential for overcorrection, as may occur with some fast-acting potassium-lowering agents. However, these associations do not mean causality and thresholds for treating hyperkalemia remain debated.

\section{Cardiac manifestations of hyperkalaemia}

Although patients with hyperkalemia can present rarely with weakness progressing to flaccid paralysis, paresthesias, or depressed deep tendon reflexes, the clinical presentation of hyperkalemia is usually benign until cardiac rhythm or conduction disorders occur. Elevation of extracellular potassium has several effects on myocardial electrophysiology that contribute to intracardiac conduction disturbances. The intracellular to extracellular potassium gradient lessens when extracellular potassium increases, thus decreasing the resting membrane potential. Elevated extracellular potassium also increases membrane permeability for potassium, lowers membrane resistance, increases repolarizing currents, and shortens transmembrane action potential duration.

While rising serum potassium initially increases conduction velocity, it decreases it at higher levels [20]. Classic hyperkalemia electrocardiographic findings include signs of hyperexcitability such as peaked T-waves (reflecting a decrease in the threshold for rapid depolarization). Further, altered conduction may manifest as PR prolongation, loss of P-waves, QRS widening, bradycardia, and ultimately a sine wave rhythm due to action potential shortening and prolongation of diastolic depolarization.

Importantly, the correlation between potassium elevation and electrocardiographic (ECG) changes is poor. Severe hyperkalemia may manifest with minimal or atypical ECG findings [1-3, 21], including nonspecific ST segment modification or pseudo-Brugada syndrome (featuring wide QRS, elevation of the ST segment, J-point elevation, $\mathrm{T}$-wave inversion). On the contrary moderate hyperkalemia $(<6 \mathrm{mmol} / \mathrm{L})$ may have life-threatening ECG findings. The electrocardiographic manifestations of hyperkalemia are largely influenced by rapid changes of plasma concentration [7], the gradient of potassium across the myocardial cell membrane, the effect of other ions (i.e., sodium, calcium), as well as underlying cardiac disease [22]. Retrospective data found a higher mortality rate in patients with hyperkalemia showing abnormal ECG findings [23]. Along these lines, chronically dialyzed patients may show no ECG signs of hyperkalemia despite high serum potassium levels. Altogether, more than the absolute serum potassium level, therapeutic strategies should be guided by the cardiac consequences of hyperkalemia identified on the ECG (Fig. 1).

\section{Causes of hyperkalemia in acutely ill patients}

Factors associated with the development of hyperkalemia can be classified into three categories, and include altered renal clearance of potassium (e.g., chronic kidney disease, acute kidney injury, renin-angiotensin-aldosterone system inhibitor), release from the intracellular space (e.g., hemolysis, rhabdomyolysis, tissue injury) and altered transfer to the intracellular space (e.g., acidosis, insulin deficit, $\beta$-adrenergic blockers, heparin) (Table 1). Hyperkalemia in the patient with normal renal function is unusual and should prompt evaluation for pseudo-hyperkalemia if no ECG abnormalities consistent with hyperkalemia are identified (false elevation of potassium due to hemolysis occurring with blood draw and not reflective of the patient's plasma potassium concentration). While concomitant medications (e.g., potassium supplements, penicillin G, digoxin, nonsteroidal anti-inflammatory drugs, renin-angiotensin-aldosterone system inhibitor, amiloride, triamterene, trimethoprim, pentamidine) are 


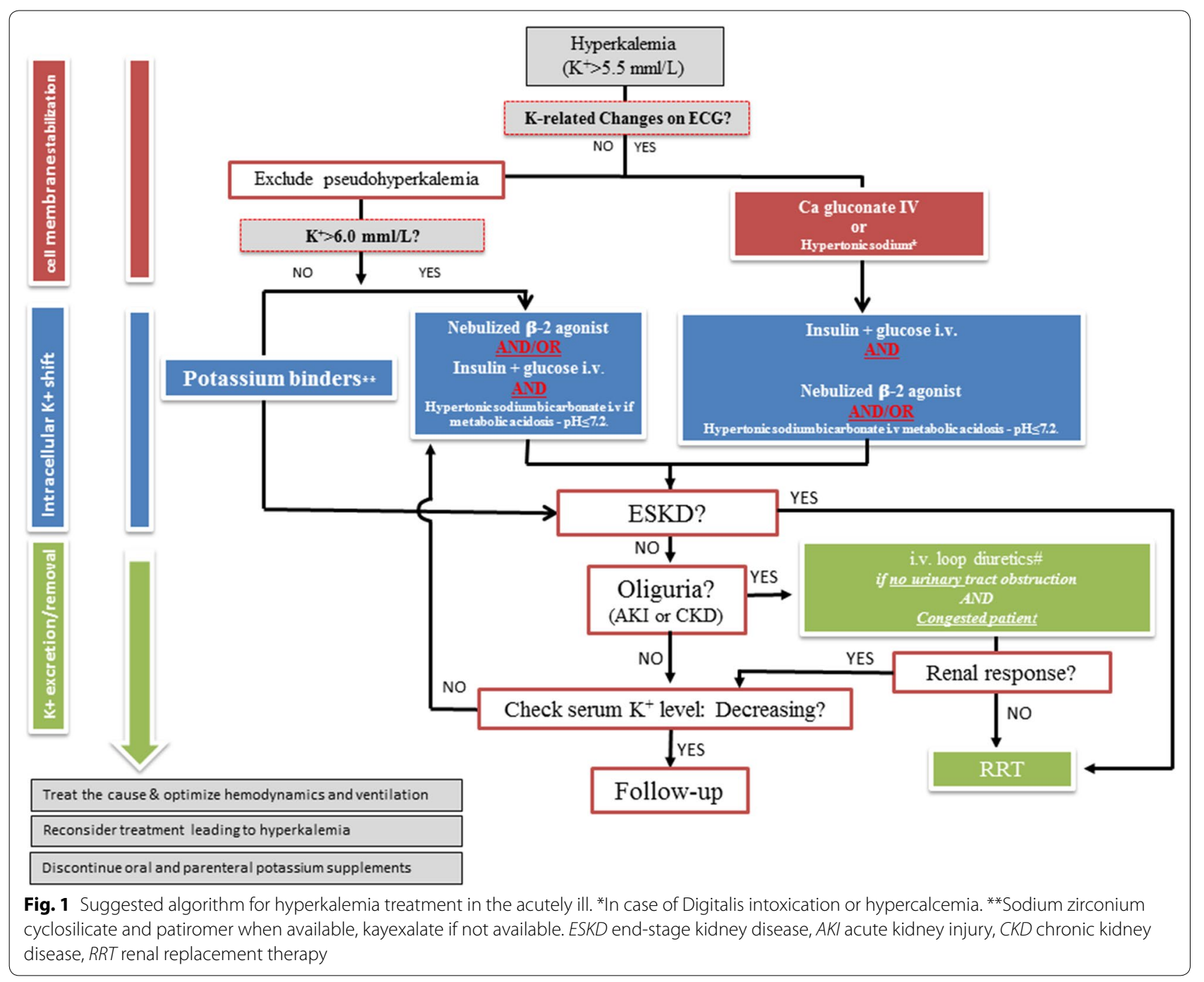

often a contributor to hyperkalemia, in our experience they are rarely the only cause in acute settings.

Since the potassium pool is mostly intracellular, alteration of cellular potassium uptake can be a major contributors to hyperkalemia [24]. Hyperchloremic acidosis is frequent in acutely ill patients [25]. According to the Stewart's theory, the main determinant of acid-base balance is the strong ion difference (SID), essentially determined by the difference between the strong cation (sodium) and the anions (chloride) [26]. A possible mechanism to explain hyperkalemia related to hyperchloremic acidosis is that mineral acids (i.e., chloric) cannot freely diffuse into the intracellular compartment, they decrease extracellular $\mathrm{pH}$. Low extracellular $\mathrm{pH}$ decreases the $\mathrm{Na}^{+}-\mathrm{H}^{+}$exchange and inhibits the inward movement of $\mathrm{Na}^{+}$. The subsequent fall in intracellular $\mathrm{Na}^{+}$reduces $\mathrm{Na}^{+}-\mathrm{K}^{+}$-ATPase activity, leading to a net decrease in $\mathrm{K}^{+}$ transfer into the cell and higher extracellular potassium levels. In this line, utilization of balanced solutions with physiological concentrations of chloride (i.e., Ringers lactate) prevents the development of mineral metabolic acidosis and is associated with lower serum potassium levels compared to $\mathrm{NaCl} 0.9 \%$ [25, 27, 28]. The effect of metabolic acidosis appears less prominent when organic acids accumulate (i.e., lactate, phosphate). This is because organic acids can passively diffuse into the intracellular compartment, resulting in a larger fall in intracellular $\mathrm{pH}$. The fall of intracellular $\mathrm{pH}$ stimulates inward $\mathrm{Na}^{+}$movement and maintains $\mathrm{Na}^{+}-\mathrm{K}^{+}$-ATPase activity, which minimizes the extracellular accumulation of potassium [29]. Ultimately, the increased intracellular $\mathrm{Na}^{+}$concentration leads to the intracellular entry of potassium [29].

A special warning should be made with regards to the use of succinylcholine, classically used to induce paralysis 
Table 1 Mechanisms contributing to the development of hyperkalemia

\begin{tabular}{ll}
\hline Mechanisms contributing to the development of hyperkalemia \\
\hline Increased extracellular $\mathrm{K}^{+}$ & Decreased $\mathrm{K}^{+}$elimination \\
\hline Tissue injury & AKI \\
Hemolysis & Hypovolemia \\
Rhabdomyolysis & Sepsis \\
Tumor lysis syndrome & Acidosis treatment \\
$\mathrm{K}^{+}$shift in extracellular space & RAAS inhibitor \\
Mineral acidosis (i.e., hyperchoride & Calcineurine inhibitor \\
acidosis) & Cardiac glycosides \\
Succinylcholine & \\
Inability to enter into myocyte & \\
Diabetes mellitus & \\
Hyperglycemia & \\
Hypertonicity & \\
$\beta_{2}$-receptor antagonists & \\
Aldosterone blockers & \\
Cardiac glycosides & \\
High acute iatrogenic $\mathrm{K}^{+}$load & \\
Increased dietary intake & \\
Blood transfusion & \\
Error of injection & \\
\hline
\end{tabular}

$K^{+}$potassium, RAAS renin-angiotensin-aldosterone system

in acutely ill patients for rapid sequence intubation. Succinylcholine induces skeletal muscle cell depolarization with an efflux of intracellular potassium by nicotinic receptor activation. In a population of critically ill patients, succinylcholine increased serum potassium on average $0.4 \mathrm{mmol} / \mathrm{L}$ (interquartile range $0-0.7 \mathrm{mmol} / \mathrm{L}$ ) [30]. It should be avoided in patients with hyperkalemia and in patients with up-regulation of nicotinic receptors, as they are at risk of greater potassium elevation. This includes those with anatomical denervation, prolonged administration of neuromuscular blocking drugs, burn injury, and prolonged immobilization [31]. Alternative to succinylcholine are available in patients at risk of hyperkalemia (i.e., rocuronium).

\section{Medical strategy}

First-line treatment in hyperkalemia with ECG abnormalities: myocardial protection

\section{Calcium salt}

The intravenous administration of a calcium salt increases the cardiac threshold potential, the speed of impulse propagation and stabilizes the myocellular membrane, thus causing almost immediate normalization of the ECG abnormalities (Fig. 2). In 1950, Merrill et al. [32] found a beneficial effect of intravenous calcium salt in 9 of 10 patients with hyperkalemia. Four years later, this was confirmed by Chamberlain et al. [33], who reported five cases of an immediate effect of intravenous calcium on ECG changes induced by severe hyperkalemia (from 8.6 to $10 \mathrm{mmol} / \mathrm{L}$ ). There are no randomized studies to show its efficacy and its indications are based on expert opinion [34]. The effect should be immediate (within $5 \mathrm{~min}$ ) when any hyperkalemia-related ECG changes are identified or suspected [33]. The protective effect may last between 30 and 60 min [35]. Calcium administration in the case of hypercalcemia may be problematic. It also increased toxicity with digoxin overdose in animal models [34]. However, this effect was found only at nonphysiologically high calcium concentrations [35]. The use of calcium in cases of hyperkalemia associated with digoxin toxicity was not associated with life-threatening dysrhythmias or mortality in human studies [36-38]. Finally, calcium may cause tissue injury (i.e., skin necrosis) in case of extravasation [39]. The recommended dose is $10-20 \mathrm{~mL}$ of a $10 \%$ calcium salt (e.g., $1-2 \mathrm{~g}$ of gluconate or chloride).

\section{Hypertonic sodium}

Infusion of hypertonic sodium also increases the action potential rising velocity in isolated cardiomyocytes [42]. In 1960, Greenstein et al. [43] studied the effect of sodium lactate, sodium bicarbonate, and sodium chloride on ECG abnormalities induced by hyperkalemia in nephrectomized dogs. Infusion of hypertonic sodium increased the action potential rising velocity, which was depressed when isolated cardiomyocytes were exposed to increasing concentrations of potassium [42]. Taken together, these results suggest that hypertonic sodium acts as a membrane stabilizer and might be considered as an alternative to calcium in hyperkalemia-induced ECG changes when infusion of calcium is at risk. Furthermore, the fluid loading associated with hypertonic sodium bicarbonate may increase the glomerular filtration rate and renal potassium excretion in volume-depleted patients.

\section{Intracellular potassium transfer Hypertonic sodium bicarbonate}

Although the data supporting the use of sodium bicarbonate as a treatment for hyperkalemia are controversial, it does have effects on serum potassium after infusion of hypertonic sodium bicarbonate. Some reported little effect on the potassium concentration in stable hemodialysis patients [44, 45]. In 1997, Ngugi et al. [46] observed that bicarbonate was less effective than salbutamol and insulin-dextrose in groups of 10 patients with end-stage renal disease (i.e., not acutely ill). Others reported effects on serum potassium. Schwarz et al. [47] reported that an infusion of 144$408 \mathrm{mmol}$ of sodium bicarbonate over $2-4 \mathrm{~h}$ lowered the serum potassium by $2-3 \mathrm{mmol} / \mathrm{L}$ in four patients with severe acidosis.

In a recent randomized controlled trial (RCT), hypertonic sodium bicarbonate $(4.2 \%)$ was administered to 
(See figure on next page.)

Fig. 2 Cardiac effect of hypertonic sodium and calcium salt during hyperkalemia. During hyperkalemia, resting membrane potential increases, derecruiting the sodium voltage gate channel Nav1.5 (left panel). Calcium salts bind to calcium-dependent calmodulin and protein kinase II (CaMKII) and activates the sodium voltage gate channel leading to an intracellular sodium entrance (right panel). Calcium salt restores the channel activity though the calcium-dependent calmodulin (CaM), recruiting the voltage-gated channel Nav1.5, increasing the intracellular sodium entrance, restore $\mathrm{dV} / \mathrm{dt}$ phase 0 action potential and increase in the resting membrane potential. Hypertonic sodium increases extracellular sodium concentration and "forces" intracellular sodium entrance (right panel). The bottom panel represents on the left the decrease of dV/dt phase 0 action potential due to hyperkalemia (Bottom left panel), restored by either calcium or hypertonic sodium (Bottom rightpanel)(Adapted from [40, 41] with authorization)

critically ill patients with severe metabolic acidaemia $(\mathrm{pH}<7.2)$ [48]. There was no difference in the primary outcome (composite of death from any cause by day 28 or 1 organ failure at day 7), but the sodium bicarbonate group had significantly lower potassium concentrations compared to the control group and required renal replacement therapy less frequently. A more recent retrospective study also reported improved survival in septic patients with AKI stage 2 or 3 and severe acidosis treated with sodium bicarbonates infusion [49]. However, the impact on serum potassium was not reported.

Metabolic alkalosis, hypernatremia, hypocalcemia, and fluid overload are potential expected side effects of sodium bicarbonate (Table 2). Hypertonic sodium bicarbonate can cause hypocalcaemia in a $\mathrm{pH}$ dependent manner and by direct calcium binding [50]. In the Jaber et al. [48] study, more patients in the bicarbonate group had ionized calcium lower than $0.9 \mathrm{mmol} / \mathrm{L}$ compared to patients in the placebo group ( $24 \%$ vs $15 \%, p=0.0167$ ) and 2 patients had a ionized calcium below $0.5 \mathrm{mmol} / \mathrm{L}$ in the bicarbonates group versus none in the placebo group. Calcium is key for cardiac contractility. In an experimental model of lactic acidosis, Kimmoun et al. [51] reported improved myocardial elastance, aortic and mesenteric vasoreactivity when sodium bicarbonate was combined with calcium compared to sodium bicarbonate alone. Severe hypocalcemia can cause myocardial dysfunction and therefore ionized calcium should be monitored and ionized hypocalcemia corrected after sodium bicarbonate infusion. Finally, even though sodium bicarbonate has been suspected of causing intracellular acidosis, this has not been confirmed in vivo [52]. We therefore recommend to use hypertonic sodium bicarbonate (e.g., $100-250 \mathrm{~mL}$ of $8.4 \%$ sodium bicarbonate over $20 \mathrm{~min}$ ) in patients with metabolic acidosis $(\mathrm{pH}<7.2)$ or in patients with a contraindication to calcium administration (patients with hypercalcemia and/or severe digoxin intoxication), whether sodium bicarbonate is efficient in reducing serum potassium in patients without severe acidosis and the impact of the mechanism of metabolic acidosis need further exploration.

\section{Insulin-dextrose}

Insulin binds to the insulin receptor on skeletal muscle, activates the sodium-potassium adenosine triphosphatase, and leads to potassium transfer from the extracellular to intracellular space (Fig. 3) [53]. Although insulin-dextrose has never been tested versus placebo for the treatment of hyperkalemia, it shows similar effects on serum potassium compared with salbutamol in a study of 20 patients $[46,54]$ but with faster decrease in serum potassium with insulin (i.e., 15 vs $30 \mathrm{~min}$ ). Of note, combination of both further lowered serum potassium compared to separate treatments. The major side effect of insulin is hypoglycemia, which has been reported to occur up to $75 \%$ in subjects, depending of the protocol $[55,56]$. One of the few blinded ED studies of hyperkalemia management found a $17 \%$ rate of clinically significant hypoglycemia after insulin-dextrose therapy [53].

Several studies suggest that a lower bolus dose of insulin may be safer. In 2 retrospective studies, similar potassium-lowering effects were found with the administration of either 5 or $10 \mathrm{U}$ of insulin (and $25 \mathrm{~g}$ of dextrose), but a higher incidence of hypoglycemia occurred with the higher insulin dose $[57,58]$. To limit hypoglycemia with the $10 \mathrm{U}$ insulin dose required using $50 \mathrm{~g}$ to $60 \mathrm{~g}$ of dextrose [59]. Another strategy is to administer weight-based insulin dosing $(0.1 \mathrm{U} / \mathrm{kg}$ of body weight up to a maximum of $10 \mathrm{U}$ ) to limit episodes of hypoglycemia without impacting potassium lowering [60]. Finally, using an infusion limited to $30 \mathrm{~min}$ led to a faster decrease in potassium, but less hypoglycemia as compared to continuous infusion [61]. Ultimately, because of the risk of hypoglycemia, blood glucose should be measured on an hourly basis for at least $2 \mathrm{~h}$, and potentially longer in the setting of renal failure [61]. While the risks of hypoglycemia have long been recognized, the risk of hyperglycemia is probably underappreciated. To summarize, using $5 \mathrm{U}$ of insulin with $25 \mathrm{~g}$ of dextrose appears an effective and safe regimen. The impact of exogenous administration of insulin and glucose on serum potassium and organ damage in this setting is unknown. Intravenous administration of high doses of glucose to limit the risk 

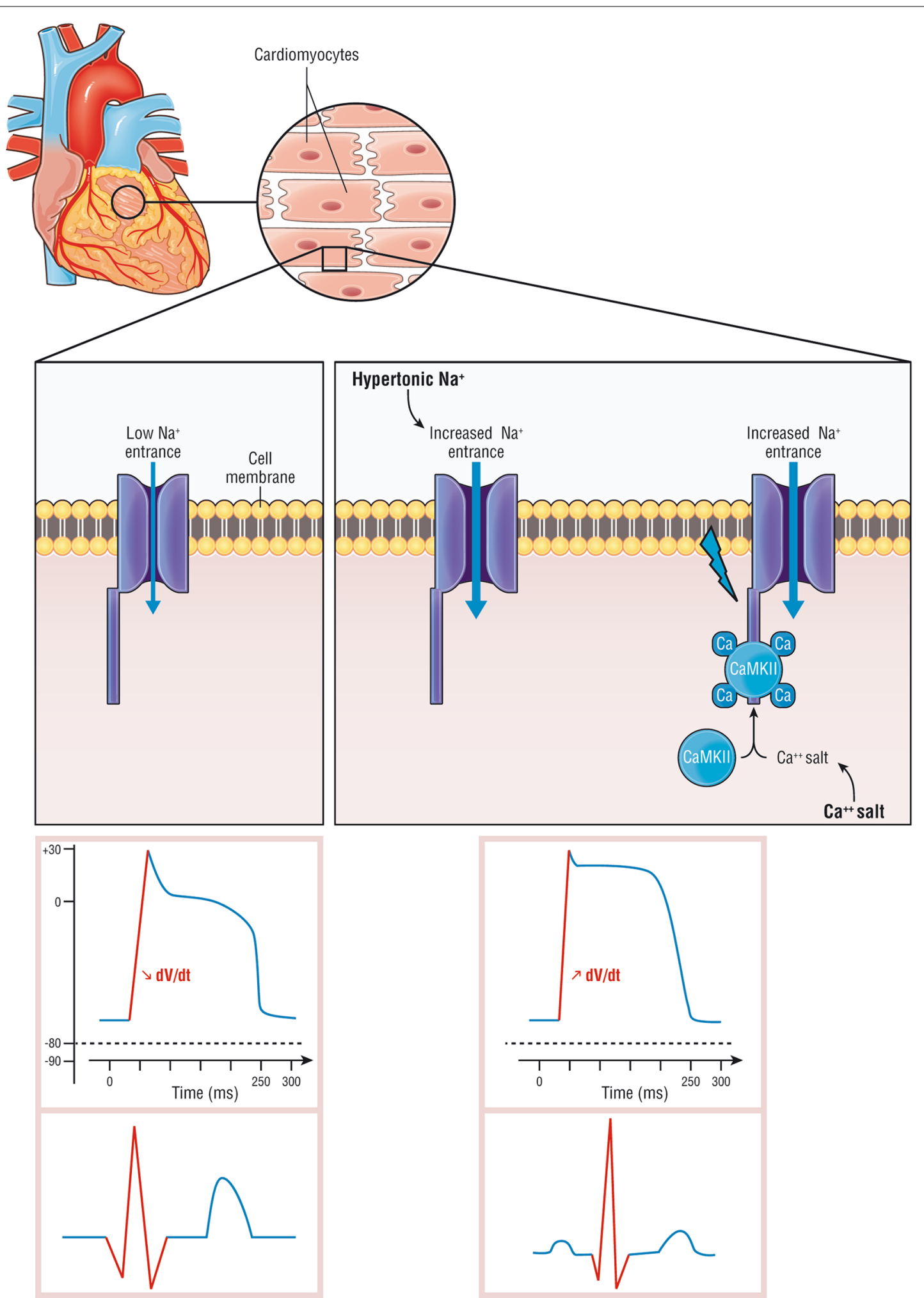
Dépret et al. Ann. Intensive Care ～（2019) 9:32

Page 7 of 16

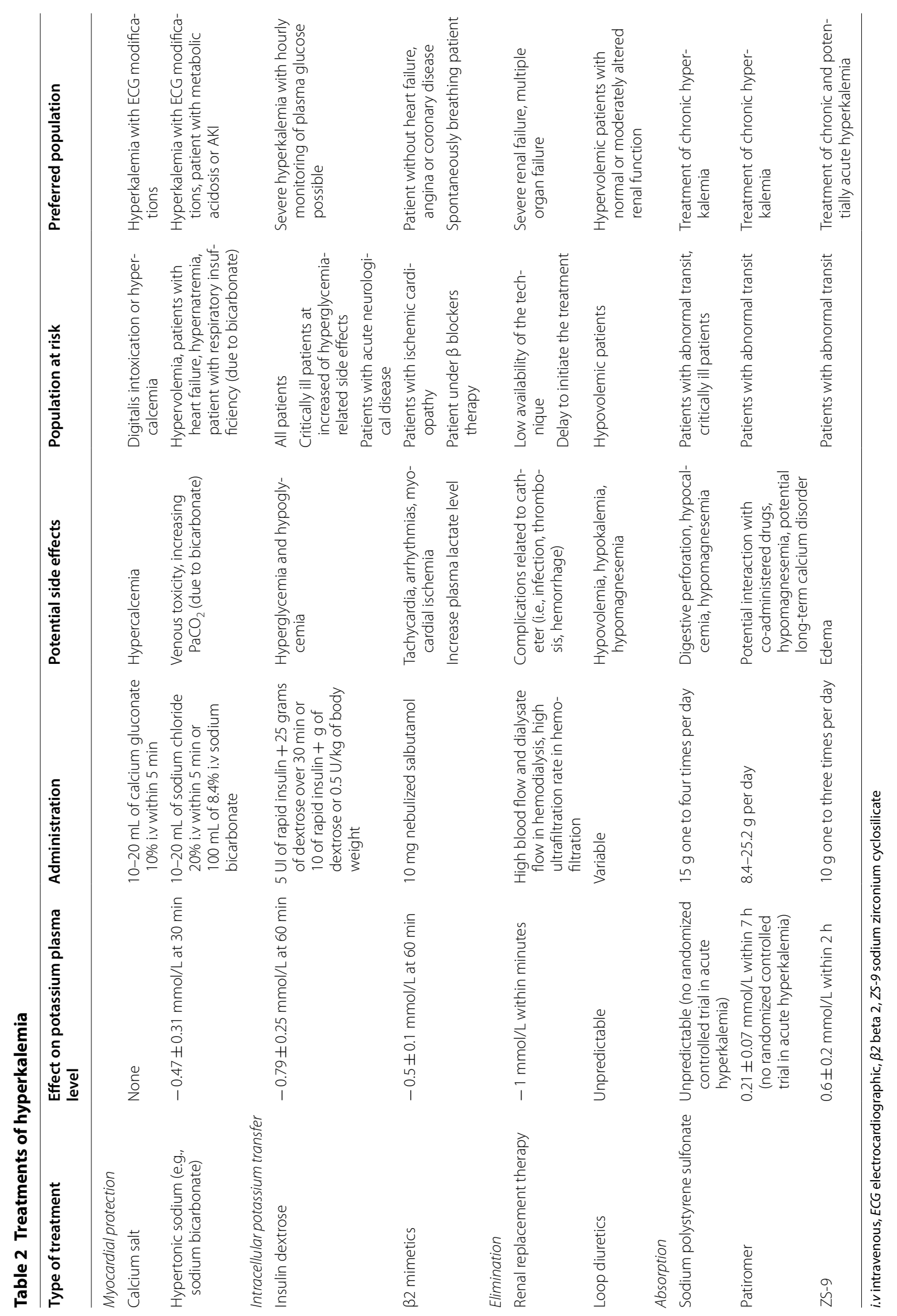




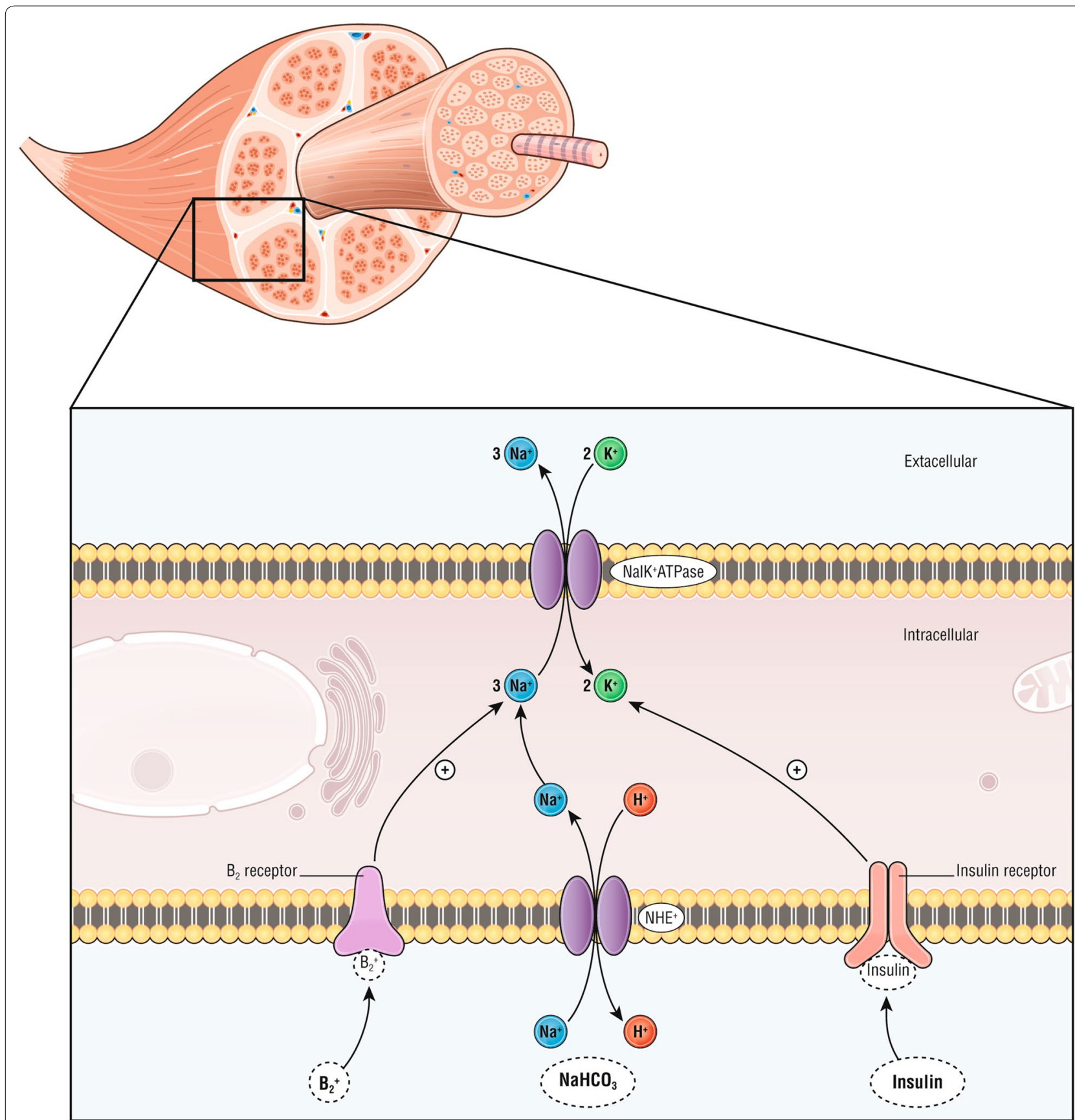

Fig. 3 Action mechanisms of plasma lowering treatments by intracellular transfer. $\beta-2$ agonist (i.e., salbutamol) binds the $\beta$-2 receptor, insulin binds insulin receptors and sodium bicarbonate $\left(\mathrm{NaHCO}_{3}\right)$ induces an intracellular entrance of sodium through the $\mathrm{Na}^{+} / \mathrm{H}^{+}$exchanger $(\mathrm{NHE})$, all activate the sodium-potassium adenosine triphosphatase ( $\mathrm{NaK}^{+}$ATPase) leading to a potassium transfer from the extracellular space to the intracellular space

of hypoglycemia may induce severe hyperglycemia, which has been associated with organ damage, vascular dysfunction and poor outcomes in different settings (i.e., heart failure, sepsis, critically ill patients) [62-64]. Critically ill patients often present with hyperglycemia and insulin resistance. We propose insulin-glucose as first-line treatment in patients with relative contraindication to $\beta-2$ agonists (Table 2) and patients with severe hyperkalemia (i.e., $\geq 6.0 \mathrm{mmol} / \mathrm{L}$ or associated with ECG changes). 


\section{$\beta$-2 agonists}

Salbutamol (e.g., albuterol) is effective at lowering potassium, without differences between nebulized or intravenous administration, in terms of its efficacy $[65,66]$ even though effectiveness appears variable. However, salbutamol administered intravenously is associated with more cardiovascular side effects than the nebulized route [67]. In one study of 10 patients treated with $10-20 \mathrm{mg}$ salbutamol, the maximal decrease in potassium ranged from 0.4 to $1.22 \mathrm{mmol} / \mathrm{L}[65,66]$. The peak effect occurred between 60 and $90 \mathrm{~min}$ after administration, and the higher salbutamol dose was more efficient in lowering potassium. Due to systemic effects of salbutamol, regardless of the route of administration, side effects, such as tachycardia may also be of concern in patients with heart failure or unstable angina. Finally, other consequences of $\beta$-2-agonists are hyperglycemia and increased plasma lactate. Impacts of treatments with $\beta$-blockers or efficacy in critically ill patients remain unexplored. Critically ill patients may present sympatho-adrenal activation (i.e., with tachycardia, vasoconstriction, hyperglycemia). We recommend the utilization of $10 \mathrm{mg}$ nebulized salbuta$\mathrm{mol}$ as first-line therapy in nonsevere hyperkalemia in spontaneous breathing patients without tachycardia.

\section{Increase potassium urinary excretion}

Loop diuretics inhibit the NKCC2 channel at the apical surface of thick ascending limb cells along the loop of Henle. NKCC2 is a sodium-potassium-chloride cotransporter that reabsorbs (directly and indirectly) up to $25 \%$ of filtered sodium and chloride. Its blockade is responsible for most natriuretic effects of loop diuretics [68]. Loop diuretic administration via the intravenous route is quickly followed by a similar dose dependent increase in both 24-h kaliuresis and natriuresis $[69,70]$. The kaliuretic effect is predominately a function of an increased tubular flow rate and a higher sodium concentration in the late nephron, both leading to an induction of the $\mathrm{Na}$ / $\mathrm{K}^{+}$-ATPase that increases potassium excretion in the distal tubules and collecting duct [70]. However, one major drawback of diuretics is the unpredictable natriuretic and kaliuretic effects, especially in patients with AKI or heart failure. These patients may be resistant to the diuretic and kaliuretic effects of diuretics, thus making this a poor strategy to control severe hyperkalemia. A "furosemide stress test" has been proposed in AKI patients to predict sustained AKI, with nonresponders defined as a urine output $<200 \mathrm{~mL}$ in the first $2 \mathrm{~h}$ after an infusion of 1.0 or $1.5 \mathrm{mg} / \mathrm{kg}$ of furosemide [71]. In these nonresponders, alternative strategies to control hyperkalemia should not be delayed. Furthermore, loop diuretics should be titrated $(0.2-0.4 \mathrm{mg} / \mathrm{kg}$ in patient without
AKI to $1-1.5 \mathrm{mg} / \mathrm{kg}$ of furosemide in patients with AKI) and only considered in patients with fluid overload after excluding low intravascular volume and with close attention to the amount of diuresis to avoid additional kidney insults resulting from iatrogenic hypovolemia. Finally, close monitoring for potential side effects, including the risk of secondary hypovolemia and other electrolytes disturbances (i.e., dysnatremia, metabolic alkalosis, hypophosphatemia, hypomagnesaemia) is needed. To conclude, except in patients with symptomatic fluid overload, diuretics should not be considered as a therapy for hyperkalemia.

\section{Gastro intestinal excretion Sodium polystyrene sulfonate (SPS)}

SPS exchanges sodium for calcium, ammonium, and magnesium in addition to potassium in the colon (Additional file 1: Figure S1) [72]. To date, no controlled trials in humans or animals have demonstrated that SPS increases fecal potassium losses, and no studies on the efficacy of SPS are available in the acute setting. However, serious gastrointestinal complications related to SPS, and attributed to sorbitol (co-administered with SPS to increase its delivery to the colon) have been described [73]. These include intestinal perforations, especially in patients with abnormal transit (e.g., patients in shock or who are immediately postoperative). Furthermore, its use has been associated with edema and increases in blood pressure-likely related to the fact that it exchanges potassium for sodium. Due to its route of administration, its delayed and highly variable onset, and the potential for serious adverse side effects [35, 73], SPS is not a treatment of choice in the acutely ill patient.

\section{Emerging treatment alternatives \\ Patiromer}

Patiromer is a sodium-free, nonabsorbed, potassiumbinding polymer, approved in the USAUS and in the European union (EU) for management of hyperkalemia. In a recent meta-analysis of phase 2 and phase 3 trials, it was associated with a decrease in serum potassium of $0.21 \pm 0.07 \mathrm{mmol} / \mathrm{L}$ within $7 \mathrm{~h}[74,75]$. Its long term efficacy and safety was also shown in a 52-week trial [76]. Side effects include minor gastrointestinal intolerance and hypomagnesemia (7.1\%) and edema due to exchange of potassium for sodium [75]. Patiromer has not been clinically tested in the emergency setting. Whether this compound may enable the maintenance of normokalemia in emergency room patients is currently being tested (REDUCE study NCT: 02933450). 


\section{Sodium zirconium cyclosilicate (ZS-9)}

ZS-9 is a crystal that is highly selective for potassium and ammonium ions exchanging sodium for potassium [77]. A recent meta-analysis of phase 2 and phase 3 studies concluded that ZS-9 was effective in maintaining normokalemia with minor gastrointestinal side effects and edema [75]. Even though ZS-9 has not been specifically compared to existing alternatives for treatment of severe hyperkalemia in emergency conditions, Kosiborod et al. [78] recently described a subgroup of 45 patients with severe hyperkalemia $(>6 \mathrm{mmol} / \mathrm{L})$ who received a $10 \mathrm{~g}$ dose of ZS-9. The median time to a serum potassium level $<6.0 \mathrm{mmol} / \mathrm{L}$ was $1.1 \mathrm{~h}$, and the median time to a level $\leq 5.5 \mathrm{mmol} / \mathrm{L}$ was $4.0 \mathrm{~h}$, suggesting that this treatment might be considered in severe acute hyperkalemia in patients with preserved gastrointestinal function. However, because of the lack of data in the acute setting and its potential delayed onset of action, it was not approved for acute hyperkalemia management in either the US or in UE. An ongoing phase 2 study (NCT03337477) is evaluating the short term efficiency of ZS-9 plus insulin-dextrose versus insulin-dextrose alone in patients with acute hyperkalemia.

\section{Renal replacement therapy Indication of Renal replacement therapy}

Severe hyperkalaemia is a key indication for renal replacement therapy (RRT) (e.g., hemodialysis or hemofiltration) in acutely ill patients with AKI [8]. However, what potassium concentration or other clinical indications (e.g., significant ECG changes) should serve as triggers for RRT remain debated [8]. However, the literature does however provide some guidance [79]. In a recent trial, a strategy of delayed RRT (with timing of RRT determined by serum creatinine or urine output) ultimately avoided RRT in many patients [80]. Not unexpectedly, medical treatment for hyperkalemia was more frequent in the delayed group, but the incidence of arrhythmias did not differ between groups. Of note, patients with potassium $>6$, or $>5.5 \mathrm{mmol} / \mathrm{L}$ despite medical treatment, were excluded, a factor limiting conclusions regarding acute therapy in those with the most severe hyperkalemia. Another trial evaluated hypertonic sodium bicarbonate in critically ill patients with severe acidaemia $(\mathrm{pH}<7.2)$. They reported the bicarbonate group had a lower serum potassium, less need for RRT, and a longer delay to RRT in those patients ultimately requiring RRT [48]. Altogether these data suggest that medical treatment of hyperkalemia (including hypertonic sodium bicarbonate in patients with metabolic acidosis) may be safe in critically ill patients with mild hyperkalemia. This medical treatment could avoid or delay RRT onset in patients with AKI.

\section{Renal replacement therapy and potassium dialysance}

Renal replacement therapies (RRT) include diffusive (i.e., hemodialysis), convective (i.e., hemofiltration) and mixed modalities (e.g., hemodiafiltration) in the acute setting. Potassium dialysance refers to the clearance of potassium in various RRT modalities. Body potassium dialysance and potassium flux depends on the gradient of potassium concentration between plasma and dialysate (or infusate using hemofiltration), blood and dialysate flow through the circuit, the modality (hemodialysis, hemofiltration, hemodiafiltration), and the dialyzer characteristics. Potassium mass transfer on the other side depends on treatment time and intracorporeal potassium kinetics (Fig. 4). Since potassium freely and totally diffuses throughout the dialyzer membrane, it is rapidly and effectively removed during hemodialysis. In the setting of high blood and dialysate flow and low dialysate potassium concentration, serum potassium drops within minutes of initiation. Since intracorporeal potassium kinetics behave as a multi-compartmental model, serum potassium will decrease more slowly after $2 \mathrm{~h}$ of hemodialysis and rebound after stopping the therapy. Of note, hyperosmolarity, or treatments shifting potassium from the extracellular to the intracellular space before the dialysis session (i.e., $\beta-2$ agonists, sodium bicarbonate, insulin, glucose), will decrease potassium dialysance.

Continuous RRT, including hemofiltration (i.e., convective technique), is the most frequently used modality in the intensive care unit. Using convective techniques, flux of potassium through the membrane depends on the ultrafiltration rate and the serum potassium level (Fig. 4). When combined techniques are used (i.e., hemodiafiltration), elimination of potassium depends mostly on the diffusive transfer through the membrane. Continuous low flow techniques have a slower decrease in serum potassium concentrations, and the serum potassium will tend to approach dialysate (with diffuse techniques) or infusate concentration (with convective techniques) within few hours after initiation without rebound. Hemofiltration using mild to high cut-off membranes also allows higher myoglobin removal in patients with rhabdomyolysis.

RRT will naturally be a second line strategy. In our view, the choice of RRT modality will largely depend on the available techniques. The efficacy and tolerance will however largely rely on RRT prescription. Using short high efficiency dialysis (intermittent dialysis) will require high blood and dialysate flow to remove sufficient amount of potassium (e.g., blood flow $250 \mathrm{~mL} / \mathrm{min}$ and dialysate flow $500 \mathrm{~mL} / \mathrm{min}$ ) allowing rapid drop of serum potassium but with a risk a rebound after stopping RRT (Fig. 4). Clearance of potassium using continuous hemofiltration is proportional to ultrafiltrate rate (Fig. 4). We 
a

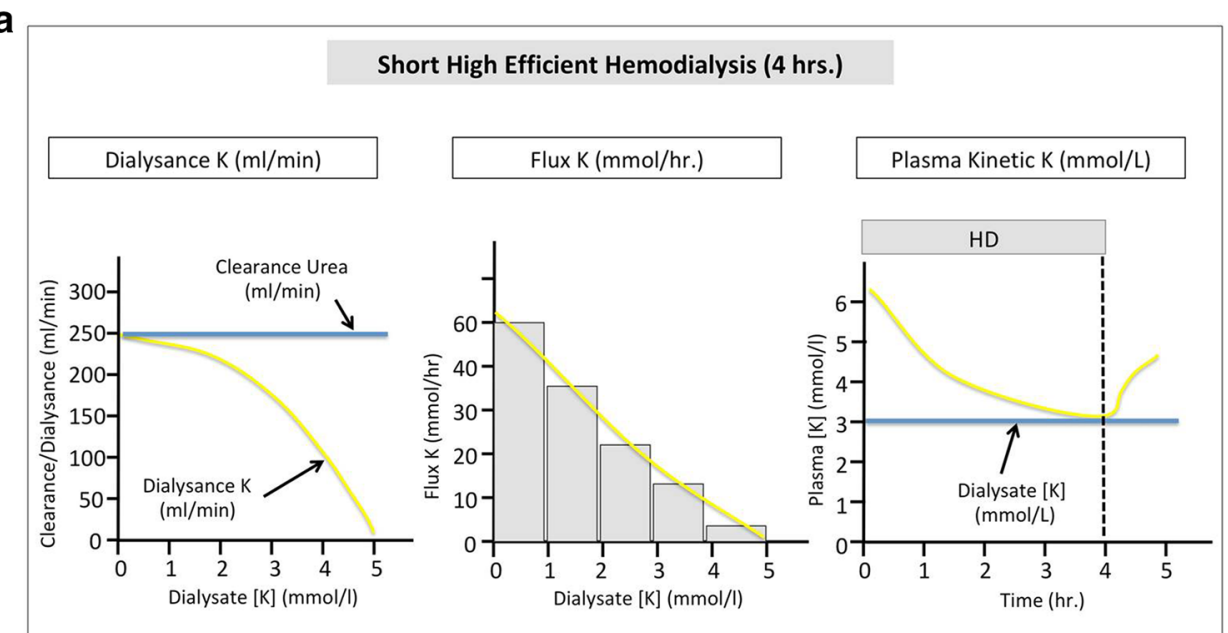

b

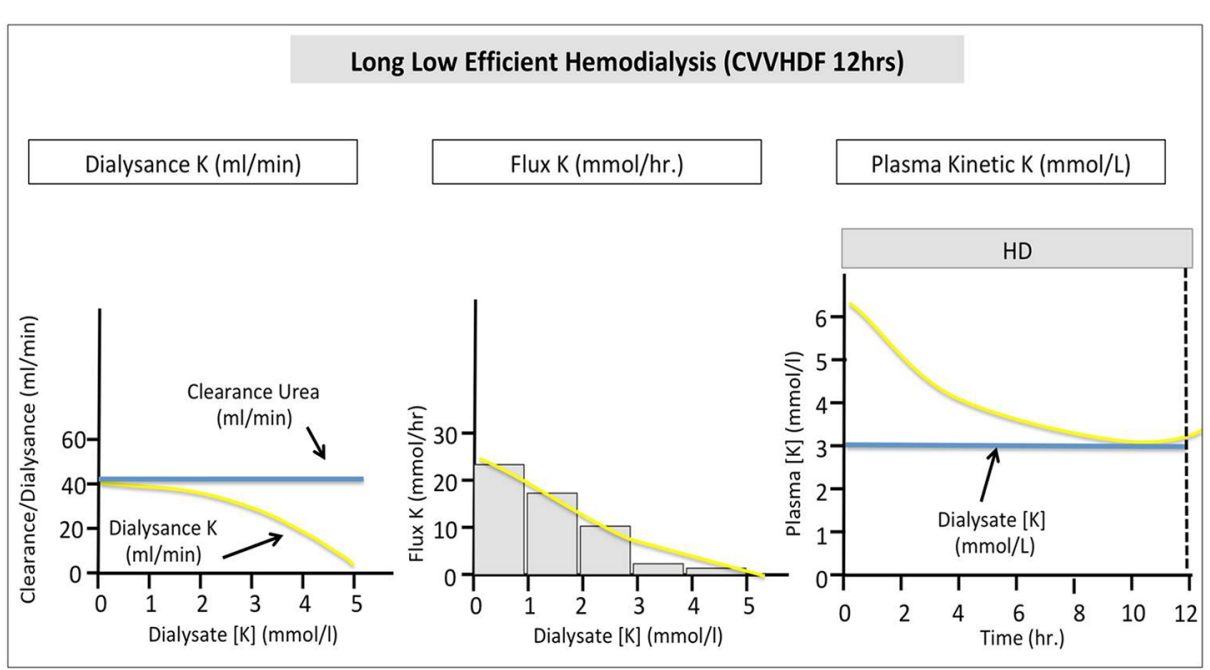

C

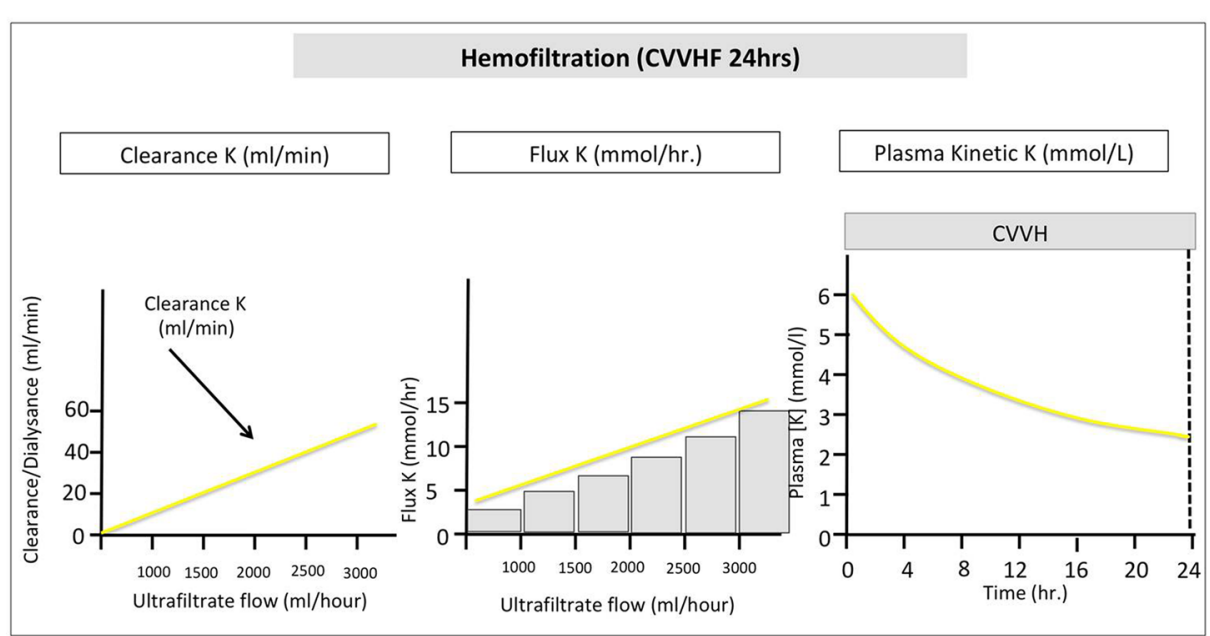

Fig. 4 Action mechanisms of hypokalemic treatments by intracellular transfer. a Potassium dialysance, flux and plasma kinetic under short high efficient hemodilaysis. b Potassium dialysance, flux and plasma kinetic under long low efficient hemodilaysis. c Potassium clearance, flux and plasma kinetic under hemofiltration. K potassium, CVVHD continuous venovenous hemodialysis, CVVHF continuous venovenous hemofiltration 
therefore advise a high ultrafiltration rate at the initiation of the technique (e.g., $\geq 45 \mathrm{~mL} / \mathrm{kg} / \mathrm{h}$ ) when using this modality. This ultrafiltration rate can be lowered when serum potassium is controlled (e.g., $25 \mathrm{~mL} / \mathrm{kg} / \mathrm{h}$ ).

Both techniques expose the patient to the risk of secondary hypokalemia. Importantly, both hyperkalemia and a rapid decrease in serum potassium are associated with cardiac events and sudden death in patients with end-stage kidney disease [81, 82]. Long interdialytic periods expose patients to consequences of hyperkalemia and cardiac conduction disorders while intradialytic periods and postdialytic periods are associated to increase cardiac excitability and arrhythmic disorders. Rapid decreases in serum potassium using a potassium dialysate concentration $\leq 2 \mathrm{mmol} / \mathrm{L}$ was associated with a doubling of risk of sudden cardiac arrest in a recent study [82]. This arrhythmogenic propensity of RRT is enhanced by simultaneous combined stresses including ischemia (hypovolemia), hypoxia, electrolyte changes (calcium, magnesium, citrate, acetate) and potential removal of cardiac medications. Studies have shown that the frequency of premature ventricular contractions during dialysis is less common when using a dialysate potassium concentration of $2.0-3.0 \mathrm{mmol} / \mathrm{L}$, compared $\leq 2.0 \mathrm{mmol} / \mathrm{L}$ [83]. More recently, Ferrey et al. [84] examined the association of dialysate potassium concentration with all-cause mortality risk in chronic hemodialysis patients. They observed that a dialysate potassium concentration of $1 \mathrm{mEq} / \mathrm{L}$ was associated with higher mortality compared to higher concentrations. Taken altogether, these data suggest using a potassium dialysate concentration $\geq 2.0 \mathrm{mmol} / \mathrm{L}$ to avoid a too rapid drop in serum potassium using dialysis. Treatment of hyperkalemia using peritoneal dialysis has been described anecdotally and appears feasible when alternatives are not readily available [85]. Alternatives to prevent rapid and profound drop of serum potassium is to use low flow techniques (i.e., continuous hemofiltration, continuous hemodialysis or slow low efficiency or extended dialysis) (Fig. 4) once acute severe hyperkalemia has been controlled. Continuous techniques will further largely prevent rebound of serum potassium observed after intermittent dialysis. Finally, extended or continuous session with high flow should be considered in patients with ongoing uncontrolled cause of hyperkalemia (i.e., rhabdomyolysis, tumor lysis syndrome).

\section{Who should be treated for hyperkalemia?}

Even though hyperkalemia has been associated with mortality in different settings [5], the potential side effects of hyperkalemia treatment should not be overlooked. Tailoring treatment to the patient condition and situation might limit the risk of under or over-treating hyperkalemia [34].

The evaluation of hyperkalemia should always include assessment for the rapid need of membrane stabilization treatment (i.e., calcium or hypertonic sodium solutions) and should be considered in patients with cardiac conduction or rhythm abnormalities (Figs. 1 and 5). When the clinical scenario and absence of ECG changes do not support the likelihood of hyperkalemia, the potassium measurement should be repeated to exclude factitious hyperkalemia (or pseudo-hyperkalemia). A result of kalemia in delocalized biochemistry (i.e., blood gas analyzer) could probably be used to detect hyperkalaemia and start a treatment in high-risk patients (e.g., patients with severe metabolic acidosis, AKI or CKD).

Efficacy and tolerance of treatment may vary widely according to the clinical scenario (Table 2). Insulin-glucose infusion appears to be appropriate for severe hyperkalemia due to its efficacy and reproducible lowering of serum potassium levels, with close serum glucose monitoring (Fig. 5). However, the impact of this regimen in critically ill patients with insulin resistance or dysglycemia remains unclear. Hypertonic sodium bicarbonate combines fluid loading, cardiac membrane stabilization and serum potassium lowering and is most appropriate in patients with severe metabolic acidosis, AKI and hypovolemia. Aerosolized $\beta-2$ agonists are more easily used in spontaneously breathing patients and appear to have similar efficacy to the insulin-dextrose combination in lowering serum potassium. However, the use of $\beta-2$ agonists in patients with cardiac hyperexcitability, baseline high sympathetic activity or with unstable coronary disease is potentially associated with severe side effects or decreased efficacy. In addition, efficacy in mechanically ventilated patients is unknown. Serial serum potassium measurements after first-line treatment allow providers to assess the initial response and need for a second line strategy. RRT is usually required in patients with severe AKI with oliguria or anuria who are not expected to rapidly recover (e.g., AKI unresponsive to hemodynamic optimization, unresponsive to diuretics), in patients with end-stage chronic kidney disease admitted for an acute condition and in the setting of severe AKI and hyperkalemia (i.e., $>6.5 \mathrm{mmol} / \mathrm{L}$ ) and in patients with hyperkalemia resistant to medical therapy [8, 34].

Finally, identification and treatment of the cause and contributing factors of hyperkalemia should be performed simultaneously. Identification of the cause of AKI and rapid correction of contributing factors of AKI may allow faster recovery. 


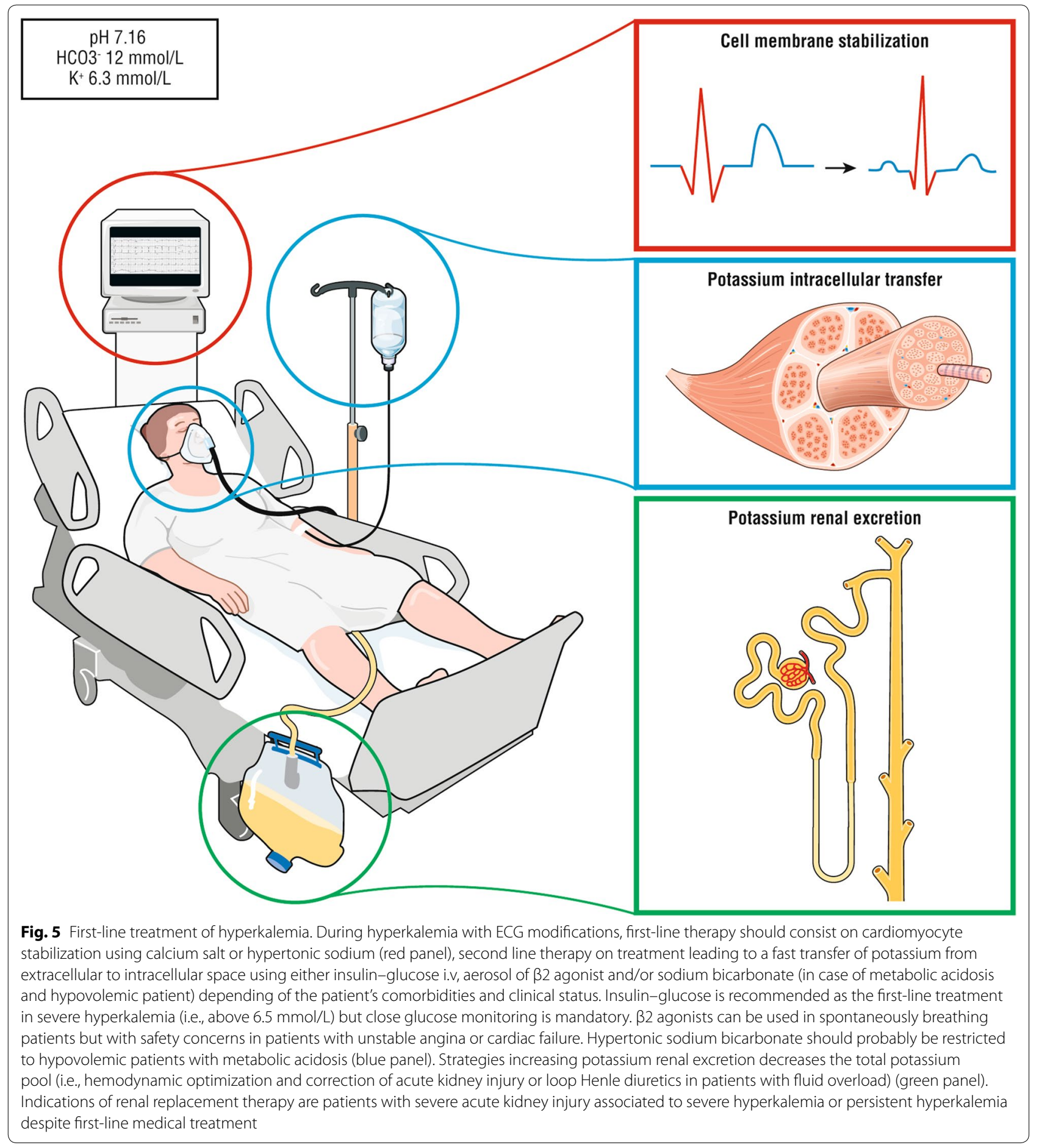

\section{Conclusion}

Recognition of hyperkalemia-related ECG changes is central in the choice of strategy to treat the patient. ECG changes should prompt urgent medical intervention including both cardiac protection and potassiumlowering treatment. Tailoring treatment of hyperkalemia to the patient condition and situation will limit the risks of treatments side effects. Efficacy and tolerance remain however poorly explored in acute setting. There is a need for further research to evaluate both efficacy and side effects of different strategies in the acute setting. 


\section{Additional file}

Additional file 1: Figure S1. Gastrointestinal absorption site of ZS-9, SPS and patiromer. The majority of potassium is in the distal gastrointestinal (GI) tract (e.g., the colon). Both sodium polystyrene sulfonate (SPS) and patiromer are concentration dependent binding (with patiromer being better than SPS). Since there is not relatively much potassium in the early part of the GI tract, SPS and patiromer have less of an effect because there is less for them to bind. Furthermore divalent cation $\left(\mathrm{Ca}^{2+}\right.$ and $\left.\mathrm{Mg}^{2+}\right)$ are inadvertently pick up as well. On the contrary, sodium zirconium cyclosilicate (ZS9), which is much more attracted to potassium and more specific than SPS or patiromer (binding coefficient much higher), that it can bind potassium in low concentration environments with less competition with divalent cation, so it starts binding earlier in the Gl tract.

\section{Abbreviations}

$\mathrm{K}^{+}$: potassium ion; AKI: acute kidney injury; ED: emergency department; ECG: electrocardiographic; SID: strong ion difference; RCT: randomized controlled trial; NKCC: Na-K-Cl cotransporter; SPS: sodium polystyrene sulfonate; US: USA; EU: European Union; ZS-9: sodium zirconium cyclosilicate; RRT: renal replacement therapy.

\section{Authors' contributions}

FD, ML: collected data, performed analysis and interpretation of the data and drafted the manuscript. FP, KL, ZR, PR: performed analysis and interpretation of the data and drafted the manuscript. All authors read and approved the final manuscript.

\section{Author details}

${ }^{1}$ GH St-Louis-Lariboisière, Department of Anesthesiology and Critical Care and Burn Unit, St-Louis Hospital, Assistance Publique-Hopitaux de Paris, Paris, France. ${ }^{2}$ University Paris Diderot, Paris, France. ${ }^{3}$ UMR INSERM 942, Institut National de la Santé et de la Recherche Médicale (INSERM), Paris, France. ${ }^{4}$ F-CRIN INI-CRCT Network, Vandœuvre-lès-Nancy, France. ${ }^{5}$ Henry JN Taub Department of Emergency Medicine, Baylor College of Medicine, Houston, TX, USA. ${ }^{6}$ Department of Medicine, University of California, San Francisco, CA, USA. ${ }^{7}$ CHRU-Nancy, INSERM 1116, Université de Lorraine, CIC Plurithématique 1433, 54000 Nancy, France.

\section{Acknowledgements}

The author thanks Pr. Bernard Canaud for his advice on the role of renal replacement therapy and editing of this part of the manuscript.

\section{Competing interests}

Dr. Dépret has nothing to disclose. Dr. Peacock reports grants and personal fees from Astra Zeneca, grants and personal fees from Relypsa, outside the submitted work. Dr. Liu reports grants from NIH: National Heart, Lung and Blood Institute, grants from $\mathrm{NIH}$ : National Institute of Diabetes and Digestive and Kidney Disease, personal fees from Achaogen, personal fees from Durect, personal fees from Z S Pharma, personal fees from Theravance, personal fees from Quark, personal fees from Potrero Med, other from Amgen, grants from American Society of Nephrology, grants from National Kidney Foundation, grants from National Policy Forum on Critical Care and Acute Renal Failure, personal fees from Baxter, outside the submitted work. Dr. Rafique reports personal fees and other from AstraZeneca, grants and personal fees from Vifor, outside the submitted work. Dr. Rossignol reports personal fees from French National Research Agency Fighting Heart Failure (ANR-15-RHU-0004), personal fees from French PIA project «Lorraine Université d'Excellence» GEENAGE (ANR15-IDEX-04-LUE) programs, outside the submitted work. Dr. Legrand reports grants from French ministry of health, grants and nonfinancial support from Sphingotec, personal fees from Fresenius, personal fees from Baxter-Hospal, and personal fees from Novartis, outside the submitted work.

\section{Availability of data and materials}

$$
\text { Not applicable. }
$$

\section{Consent for publication}

Not applicable.
Ethics approval and consent to participate

Not applicable.

\section{Funding}

Not applicable.

\section{Publisher's Note}

Springer Nature remains neutral with regard to jurisdictional claims in published maps and institutional affiliations.

Received: 9 November 2018 Accepted: 22 February 2019

Published online: 28 February 2019

\section{References}

1. Mattu A, Brady WJ, Robinson DA. Electrocardiographic manifestations of hyperkalemia. Am J Emerg Med. 2000;18:721-9.

2. Freeman K, Feldman JA, Mitchell P, Donovan J, Dyer KS, Eliseo L, et al. Effects of presentation and electrocardiogram on time to treatment of hyperkalemia. Acad Emerg Med. 2008;15:239-49.

3. Montague BT, Ouellette JR, Buller GK. Retrospective review of the frequency of ECG changes in hyperkalemia. Clin J Am Soc Nephrol. 2008:3:324-30

4. Truhláŕ A, Deakin CD, Soar J, Khalifa GEA, Alfonzo A, Bierens JJ, et al. European resuscitation council guidelines for resuscitation 2015. Resuscitation. 2015;95:148-201.

5. Khanagavi J, Gupta T, Aronow WS, Shah T, Garg J, Ahn C, et al. Hyperkalemia among hospitalized patients and association between duration of hyperkalemia and outcomes. Arch Med Sci. 2014;2:251-7.

6. Phillips BM, Milner S, Zouwail S, Roberts G, Cowan M, Riley SG, et al. Severe hyperkalaemia: demographics and outcome. Clin Kidney J. 2014;7:127-33.

7. Winkler AW, Hoff HE, Smith PK. Electrocardiographic changes and concentration of potassium in serum following intravenous injection of potassium chloride. Am J Physiol Leg Content. 1938;124:478-83.

8. Kellum JA, Lameire N, Aspelin P, Barsoum RS, Burdmann EA, Goldstein SL, et al. Work group membership. Kidney Int. 2012;2:1.

9. Lee Hamm L, Hering-Smith KS, Nakhoul NL. Acid-base and potassium homeostasis. Semin Nephrol. 2013;33:257-64.

10. Jain N, Kotla S, Little BB, Weideman RA, Brilakis ES, Reilly RF, et al. Predictors of hyperkalemia and death in patients with cardiac and renal disease. Am J Cardiol. 2012;109:1510-3.

11. Goyal A, Spertus JA, Gosch K, Venkitachalam L, Jones PG, Van den Berghe $G$, et al. Serum potassium levels and mortality in acute myocardial infarction. JAMA. 2012;307:157.

12. Brunelli SM, Du Mond C, Oestreicher N, Rakov V, Spiegel DM. Serum potassium and short-term clinical outcomes among hemodialysis patients: impact of the long interdialytic interval. Am J Kidney Dis. 2017;70:21-9

13. Collins AJ, Pitt B, Reaven N, Funk S, McGaughey K, Wilson D, et al. Association of serum potassium with all-cause mortality in patients with and without heart failure, chronic kidney disease, and/or diabetes. Am J Nephrol. 2017;46:213-21.

14. McMahon GM, Mendu ML, Gibbons FK, Christopher KB. Association between hyperkalemia at critical care initiation and mortality. Intensive Care Med. 2012;38:1834-42.

15. Legrand M, Ludes P-O, Massy Z, Rossignol P, Parenica J, Park J-J, et al. Association between hypo- and hyperkalemia and outcome in acute heart failure patients: the role of medications. Clin Res Cardiol Off J Ger Card Soc. 2018;107:214-21.

16. Hoss S, Elizur Y, Luria D, Keren A, Lotan C, Gotsman I. Serum potassium levels and outcome in patients with chronic heart failure. Am J Cardiol. 2016;118:1868-74.

17. Ahmed A, Zannad F, Love TE, Tallaj J, Gheorghiade M, Ekundayo OJ, et al. A propensity-matched study of the association of low serum potassium levels and mortality in chronic heart failure. Eur Heart J. 2007;28:1334-43.

18. Luo J, Brunelli SM, Jensen DE, Yang A. Association between serum potassium and outcomes in patients with reduced kidney function. Clin J Am Soc Nephrol. 2016;11:90-100. 
19. Rossignol P, Girerd N, Bakris G, Vardeny O, Claggett B, McMurray JJV, et al. Impact of eplerenone on cardiovascular outcomes in heart failure patients with hypokalaemia. Eur J Heart Fail. 2017;19:792-9.

20. Lyons CJ, Burgess MJ, Abildskov JA. Effects of acute hyperkalemia on cardiac excitability. Am Heart J. 1977:94:755-63.

21. Aslam S, Friedman EA, Ifudu O. Electrocardiography is unreliable in detecting potentially lethal hyperkalaemia in haemodialysis patients. Nephrol Dial Transplant. 2002;17:1639-42.

22. Burchell HB. Electrocardiographic changes related to disturbances in potassium metabolism. J Lancet. 1953;73:235-8.

23. Durfey N, Lehnhof B, Bergeson A, Durfey S, Leytin V, McAteer K, et al. Severe hyperkalemia: Can the electrocardiogram risk stratify for shortterm adverse events? West J Emerg Med. 2017;18:963-71.

24. Kovesdy CP, Appel LJ, Grams ME, Gutekunst L, McCullough PA, Palmer BF, et al. Potassium homeostasis in health and disease: a scientific workshop cosponsored by the National Kidney Foundation and the American Society of Hypertension. J Am Soc Hypertens. 2017:11:783-800

25. Yunos NM, Kim IB, Bellomo R, Bailey M, Ho L, Story D, et al. The biochemical effects of restricting chloride-rich fluids in intensive care. Crit Care Med. 2011;39:2419-24.

26. Stewart PA. Independent and dependent variables of acid-base control. Respir Physiol. 1978;33:9-26.

27. O'Malley CMN, Frumento RJ, Hardy MA, Benvenisty Al, Brentjens TE, Mercer JS, et al. A randomized, double-blind comparison of lactated Ringer's solution and $0.9 \% \mathrm{NaCl}$ during renal transplantation. Anesth Analg. 2005;100:1518-24.

28. Khajavi MR, Etezadi F, Moharari RS, Imani F, Meysamie AP, Khashayar P, et al. Effects of normal saline vs. lactated Ringer's during renal transplantation. Ren Fail. 2008;30:535-9.

29. Palmer BF. Regulation of potassium homeostasis. Clin J Am Soc Nephrol. 2015;10:1050-60.

30. Blanié A, Ract C, Leblanc P-E, Cheisson G, Huet O, Laplace C, et al. The limits of succinylcholine for critically ill patients. Anesth Analg. 2012;115:873-9.

31. Strayer RJ. Succinylcholine, rocuronium, and hyperkalemia. Am J Emerg Med. 2016;34:1705-6.

32. Merrill JP, Levine HD, Somerville W, Smith S. Clinical recognition and treatment of acute potassium intoxication. Ann Intern Med. 1950;33:797.

33. Chamberlain MJ. Emergency treatment of hyperkalaemia. Lancet Lond Engl. 1964;1:464-7.

34. Rossignol P, Legrand M, Kosiborod M, Hollenberg SM, Peacock WF, Emmett $\mathrm{M}$, et al. Emergency management of severe hyperkalemia: guideline for best practice and opportunities for the future. Pharmacol Res. 2016;113:585-91.

35. Alfonzo AVM, Isles C, Geddes C, Deighan C. Potassium disorders-clinical spectrum and emergency management. Resuscitation. 2006;70:10-25.

36. Smith PK. Calcium and digitalis synergism: the toxicity of calcium salts injected intravenously into digitalized animals. Arch Intern Med. 1939;64:322.

37. Nola GT, Pope S, Harrison DC. Assessment of the synergistic relationship between serum calcium and digitalis. Am Heart J. 1970;79:499-507.

38. Levine M, Nikkanen $H$, Pallin DJ. The effects of intravenous calcium in patients with digoxin toxicity. J Emerg Med. 2011;40:41-6.

39. Pacheco Compaña FJ, Midón Míguez J, de Toro Santos FJ. Lesions associated with calcium gluconate extravasation: presentation of 5 clinical cases and analysis of cases published. Ann Plast Surg. 2017;79:444-9.

40. Robert T, Joseph A, Mesnard L. Calcium salt during hyperkalemia. Kidney int. 2016;90:451-2.

41. Robert T, Burbach M, Joseph A, Mesnard L. Sodium is the secret re-agent of bicarbonate therapy during hyperkalemia. Kidney Int. 2016;90:450-1.

42. Ballantyne F, Davis LD, Reynolds EW. Cellular basis for reversal of hyperkalemic electrocardiographic changes by sodium. Am J Physiol. 1975;229:935-40

43. Greenstein S, Goldburgh WP, Guzman SV, Bellet S. A comparative analysis of molar sodium lactate and other agents in the treatment of induced hyperkalemia in nephrectomized dogs. Circ Res. 1960;8:223-33.

44. Gutierrez R, Schlessinger F, Oster JR, Rietberg B, Perez GO. Effect of hypertonic versus isotonic sodium bicarbonate on plasma potassium concentration in patients with end-stage renal disease. Miner Electrolyte Metab. 1991;17:297-302.

45. Allon M, Shanklin N. Effect of bicarbonate administration on plasma potassium in dialysis patients: interactions with insulin and albuterol. Am J Kidney Dis Off J Natl Kidney Found. 1996;28:508-14.

46. Ngugi NN, McLigeyo SO, Kayima JK. Treatment of hyperkalaemia by altering the transcellular gradient in patients with renal failure: effect of various therapeutic approaches. East Afr Med J. 1997;74:503-9.

47. Schwarz KC, Cohen BD, Lubash GD, Rubin AL. Severe acidosis and hyperpotassemia treated with sodium bicarbonate infusion. Circulation. 1959;19:215-20.

48. Jaber S, Paugam C, Futier E, Lefrant J-Y, Lasocki S, Lescot T, et al. Sodium bicarbonate therapy for patients with severe metabolic acidaemia in the intensive care unit (BICAR-ICU): a multicentre, open-label, randomised controlled, phase 3 trial. Lancet. 2018;392:31-40.

49. Zhang Z, Zhu C, Mo L, Hong Y. Effectiveness of sodium bicarbonate infusion on mortality in septic patients with metabolic acidosis. Intensive Care Med. 2018. https://doi.org/10.1007/s00134-018-5379-2.

50. Cooper DJ, Walley KR, Wiggs BR, Russell JA. Bicarbonate does not improve hemodynamics in critically ill patients who have lactic acidosis. A prospective, controlled clinical study. Ann Intern Med. 1990;112:492-8.

51. Kimmoun A, Ducrocq N, Sennoun N, Issa K, Strub C, Escanyé J-M, et al. Efficient extra- and intracellular alkalinization improves cardiovascular functions in severe lactic acidosis induced by hemorrhagic shock. Anesthesiology. 2014;120:926-34.

52. Levraut J, Labib Y, Chave S, Payan P, Raucoules-Aime M, Grimaud D. Effect of sodium bicarbonate on intracellular pH under different buffering conditions. Kidney Int. 1996;49:1262-7.

53. Ho K. A critically swift response: insulin-stimulated potassium and glucose transport in skeletal muscle. Clin J Am Soc Nephrol. 2011;6:1513-6.

54. Allon M, Copkney C. Albuterol and insulin for treatment of hyperkalemia in hemodialysis patients. Kidney Int. 1990;38:869-72.

55. Rafique Z, Kosiborod M, Clark CL, Singer AJ, Turner S, Miller J, et al. Study design of Real World Evidence for Treatment of Hyperkalemia in the Emergency Department (REVEAL-ED): a multicenter, prospective, observational study. Clin Exp Emerg Med. 2017:4:154-9.

56. Peacock WF, Miller J, Char D, Clark CL, Singer AJ, Rafique Z, et al. 1* Burden of hyperkalemia and treatment patterns in the Emergency Department setting: results from the REVEAL-ED Study. Ann Emerg Med. 2016;68:S1.

57. LaRue H, Peksa GD, Shah S. A comparison of insulin doses for the treatment of hyperkalemia in patients with renal insufficiency. Pharmacother J Hum Pharmacol Drug Ther. 2017. https://doi.org/10.1002/phar.2038.

58. McNicholas BA, Pham MH, Carli K, Chen CH, Colobong-Smith N, Anderson AE, et al. Treatment of hyperkalemia with a low-dose insulin protocol is effective and results in reduced hypoglycemia. Kidney Int Rep. 2018:3:328-36

59. Coca A, Valencia AL, Bustamante J, Mendiluce A, Floege J. Hypoglycemia following intravenous insulin plus glucose for hyperkalemia in patients with impaired renal function. PLoS ONE. 2017;12:e0172961.

60. Wheeler DT, Schafers SJ, Horwedel TA, Deal EN, Tobin GS. Weight-based insulin dosing for acute hyperkalemia results in less hypoglycemia: hyperkalemia treatment and hypoglycemia. J Hosp Med. 2016;11:355-7.

61. Harel Z, Kamel KS. Optimal dose and method of administration of intravenous insulin in the management of emergency hyperkalemia: a systematic review. PLoS ONE. 2016;11:e0154963.

62. Capes SE, Hunt D, Malmberg K, Gerstein HC. Stress hyperglycaemia and increased risk of death after myocardial infarction in patients with and without diabetes: a systematic overview. Lancet. 2000;355:773-8.

63. King JT, Goulet JL, Perkal MF, Rosenthal RA. Glycemic control and infections in patients with diabetes undergoing noncardiac surgery. Ann Surg. 2011;253:158-65.

64. Van den Berghe G, Wouters P, Weekers F, Verwaest C, Bruyninckx F, Schetz $M$, et al. Intensive insulin therapy in critically ill patients. N Engl J Med. 2001;345:1359-67.

65. Allon M. Nebulized albuterol for acute hyperkalemia in patients on hemodialysis. Ann Intern Med. 1989;110:426.

66. Mandelberg A, Krupnik Z, Houri S, Smetana S, Gilad E, Matas Z, et al. Salbutamol metered-dose inhaler with spacer for hyperkalemia: How fast? How safe? Chest J. 1999:115:617-22.

67. Liou H-H, Chiang S-S, Wu S-C, Huang T-P, Campese VM, Smogorzewski $M$, et al. Hypokalemic effects of intravenous infusion or nebulization of 
salbutamol in patients with chronic renal failure: comparative study. Am J Kidney Dis. 1994;23:266-71.

68. Ellison DH, Felker GM. Diuretic treatment in heart failure. N Engl J Med. 2017;377:1964-75.

69. Reyes AJ. Effects of diuretics on renal excretory function. Eur Heart J. 1992;13:15-21.

70. Reyes AJ. Renal excretory profiles of loop diuretics: consequences for therapeutic application. J Cardiovasc Pharmacol. 1993;22(Suppl 3):S11-23.

71. Chawla LS, Davison DL, Brasha-Mitchell E, Koyner JL, Arthur JM, Shaw AD, et al. Development and standardization of a furosemide stress test to predict the severity of acute kidney injury. Crit Care. 2013;17:R207.

72. Evans BM, Jones NC, Milne MD, Yellowlees $\mathrm{H}$. lon-exchange resins in the treatment of anuria. Lancet Lond Engl. 1953;265:791-5.

73. Harel Z, Harel S, Shah PS, Wald R, Perl J, Bell CM. Gastrointestinal adverse events with sodium polystyrene sulfonate (kayexalate) use: a systematic review. Am J Med. 2013;126:264.e9-24.

74. Bushinsky DA, Williams GH, Pitt B, Weir MR, Freeman MW, Garza D, et al. Patiromer induces rapid and sustained potassium lowering in patients with chronic kidney disease and hyperkalemia. Kidney Int. 2015;88:1427-33.

75. Meaney CJ, Beccari MV, Yang Y, Zhao J. Systematic review and meta-analysis of patiromer and sodium zirconium cyclosilicate: a new armamentarium for the treatment of hyperkalemia. Pharmacother J Hum Pharmacol Drug Ther. 2017;37:401-11.

76. Bakris GL, Pitt B, Weir MR, Freeman MW, Mayo MR, Garza D, et al. Effect of patiromer on serum potassium level in patients with hyperkalemia and diabetic kidney disease: the AMETHYST-DN randomized clinical trial. JAMA. 2015;314:151.
77. Stavros F, Yang A, Leon A, Nuttall M, Rasmussen HS. Characterization of structure and function of ZS-9, a $\mathrm{K}^{+}$selective ion trap. PLOS ONE. 2014;9:e114686.

78. Kosiborod M, Peacock WF, Packham DK. Sodium zirconium cyclosilicate for urgent therapy of severe hyperkalemia. N Engl J Med. 2015;372:1577-8.

79. Lameire N, Van Biesen W, Vanholder R. Acute renal failure. Lancet. 2005;365:417-30.

80. Gaudry S, Hajage D, Schortgen F, Martin-Lefevre L, Pons B, Boulet E, et al. Initiation strategies for renal-replacement therapy in the intensive care unit. N Engl J Med. 2016;375:122-33.

81. Kovesdy CP, Regidor DL, Mehrotra R, Jing J, McAllister CJ, Greenland $S$, et al. Serum and dialysate potassium concentrations and survival in hemodialysis patients. Clin J Am Soc Nephrol. 2007;2:999-1007.

82. Pun PH, Lehrich RW, Honeycutt EF, Herzog CA, Middleton JP. Modifiable risk factors associated with sudden cardiac arrest within hemodialysis clinics. Kidney Int. 2011;79:218-27.

83. Morrison G, Michelson EL, Brown S, Morganroth J. Mechanism and prevention of cardiac arrhythmias in chronic hemodialysis patients. Kidney Int. 1980;17:811-9.

84. Ferrey A, You AS, Kovesdy CP, Nakata T, Veliz M, Nguyen DV, et al. Dialysate potassium and mortality in a prospective hemodialysis cohort. Am J Nephrol. 2018;47:415-23.

85. Roseman DA, Schechter-Perkins EM, Bhatia JS. Treatment of life-threatening hyperkalemia with peritoneal dialysis in the ED. Am J Emerg Med. 2015;33:473.e3-5.

\section{Submit your manuscript to a SpringerOpen ${ }^{\circ}$ journal and benefit from:}

- Convenient online submission

- Rigorous peer review

- Open access: articles freely available online

- High visibility within the field

- Retaining the copyright to your article

Submit your next manuscript at $\boldsymbol{\nabla}$ springeropen.com 